American Journal of Applied Sciences 6 (5): 876-881, 2009

ISSN 1546-9239

(C) 2009 Science Publications

\title{
Presence and Origin of Fluoride in the Complex Terminal Water of Ouargla Basin (Northern Sahara of Algeria)
}

\author{
${ }^{1}$ Imed Eddine Nezli, ${ }^{2}$ Samia Achour, ${ }^{1}$ Mohamed Djidel and ${ }^{1}$ Saïd Attalah \\ ${ }^{1}$ Laboratory of Protection of Ecosystems in Arid and Semi-Arid Areas, \\ Department of Geology, ITE, P.O. Box 511,University Kasdi Merbah, Ouargla \\ ${ }^{2}$ Laboratory of Underground and Surface Hydraulics Research "LARHYSS" \\ University Mohamed Kheider, Biskra
}

\begin{abstract}
Problem statement: The underground waters in the oriental regions of the Algerian Sahara, present real chemical quality problems. Their content in fluorides always exceeds the limit of the recommended levels. That is $0.8 \mathrm{mg} \mathrm{L}^{-1}$, according to the maximum temperature in the region. Combined to a high salinity, it affects the health of the population living around the region. The present work, deals with the presence of fluoride and the geochemical origin in the Complex Terminal aquifer of Ouargla, rarely examined in the Algerian Sahara. Approach: Is based on the following aspects: Sampling and physico-chemicals analysis of water, statistical treatment of the physicochemical water parameters and simulation to natural and isotherm $25^{\circ} \mathrm{C}$ evaporation of water parameters. Results: The results show the presence of fluoride in the studied water. The rates vary between 1 and $2 \mathrm{mg} \mathrm{L}^{-1}$. The calculation of water saturation index in relation with the preponderant minerals, using the thermodynamic model «phreeqci» reveals a sensitivity of carbonate minerals towards precipitation and dissolution of evaporitic minerals and clayey fluorides as well. Conclusions/Recommendations: The increasing alkalinity of water in contact with the aquifer during long periods of stay decreases the chemical activity of calcium and helps with alteration of clayey minerals and fluoride as a necessary condition for a possible fluorite mineralization. Knowing the origin of that fluoridation leads to possible solutions, through the optimization of a water treatment meets the standards.
\end{abstract}

Key words: Ouargla, complex terminal, geochemistry, fluoride, saturation index.

\section{INTRODUCTION}

The underground water resources in the basin of Ouargla, are represented, as everywhere in the Sahara regions of northern Algeria and Tunisia by two major aquifer systems superimposed: The Continental Intercalaire (CI) and the Complex Terminal (CT), which contain large reserves estimated at $31000 \times 10^{9} \mathrm{~m}^{3}$. The current levies are around 1.4 billion $\mathrm{m}^{3}$ a year, resulting in practical terms, by continuing drawdown of $\mathrm{CT}$ aquifer ${ }^{[7]}$. The groundwater is highly mineralized (over $5000 \mathrm{mg}$ $\left.\mathrm{L}^{-1}\right)^{[7]}$.

The concentrations of fluoride in the water of CT often exceed the recommended levels by the World Health Organization (WHO). It is between 0.6 and $0.8 \mathrm{mg} \mathrm{\textrm {L } ^ { - 1 }}$, according to the maximum diurnal temperature in the region. The problem was raised throughout the region, by various studies on water quality in the Algerian Sahara ${ }^{[3]}$.
The Complex Terminal aquifer is heterogeneous and made of sand, sandstone, clay, lime and evaporates, containing, theoretically, in their aquifer matrix significant and variable proportions of fluoride. However, the lack of detailed knowledge about the mineralogy of these formations in the northern Sahara is an obstacle to understand the hydro-geochemical process of fluoride mineralization in the waters of the Complex Terminal. To face this failure, this study attempts highlight the relationship between fluoride mineralization in water and the geology of different aquifers. The approach is based on the following aspects:

- Water sampling and physico-chemical analysis

- Statistical treatment of the physico-chemical parameters of water to get a global approach of the water's chemical composition process of acquisition

Corresponding Author: Imed Eddine Nezli, Laboratory of Protection of Ecosystems in Arid and Semi-arid Areas, Department of Geology, ITE, P.O. Box 511, University Kasdi Merbah, Ouargla 
- Simulation to natural and isotherm $25^{\circ} \mathrm{C}$ evaporation of the water parameters to clarify the mechanisms of acquisition of water fluoridation

\section{MATERIALS AND METHODS}

The Valley of Ouargla (Fig. 1), corresponding to a major depression, which covers an area of $750 \mathrm{~km}^{2}$ around the quaternary bed of lower fossil valley in of oued M'ya. The climate of Ouargla is Saharan hyper arid, with temperate winters and a permanent drought. Precipitation is about $43.20 \mathrm{~mm}_{\text {year }}{ }^{-1}$ and still below the double temperatures whose maximum average is about $42.69^{\circ} \mathrm{C}$. The total Potential of EvapoTranspiration (PET) is about $2758.80 \mathrm{~mm}$ year $^{-1}$, almost 60 times that of rainfall.

The underground of Ouargla basin contains four aquifers used in urban and agricultural activities:

Sandstones and sandy clays of the Continental Intercalaire (CI), containing the so-called Albian water, whoses thickness is about $600 \mathrm{~m}$, located at a depth of $1500 \mathrm{~m}$ :

- Limestone, with containing water of SenonoEocene carbonate whose thickness is about $300 \mathrm{~m}$, located at a depth of $200 \mathrm{~m}$

- All detritics of the continental formation (sand, clay and evaporites) with the water of the MioPliocène, located at a depth of $20 \mathrm{~m}$ to $100 \mathrm{~m}$ and thick of approximately $100 \mathrm{~m}$

- Quaternary sands with groundwater table, located at a depth of less than $2 \mathrm{~m}$

All the permeable formations contained in the series from the Cenomanian to Mio-Pliocene, are grouped, by Conrad Kilian (1931), under the name «Complex Terminal Water». The geological age of water determined by radiocarbon, is estimated between 10,000 and 20,000 years $\mathrm{BP}^{[4]}$. Therefore, the water is ancient, having taken place in the reservoir of sedimentary formations of the Complex Terminal water during long periods.

Nineteen (19) samples of water (Fig. 1) are collected (February 2002) from ten (10) wells in MioPliocene (MP1,...MP10) and nine (09) wells in Senono-Eocene (SE1,...SE9) using in plastic bottles. Before to be used, the bottles were treated with nitric acid, then washed with distilled water and dripped before being washed three times with the water to be analyzed.

The analyses are conducted in the laboratory of the National Agency of Hydraulics Resources (ANRH) of Ouargla according to the technical standard ${ }^{[9]}$.

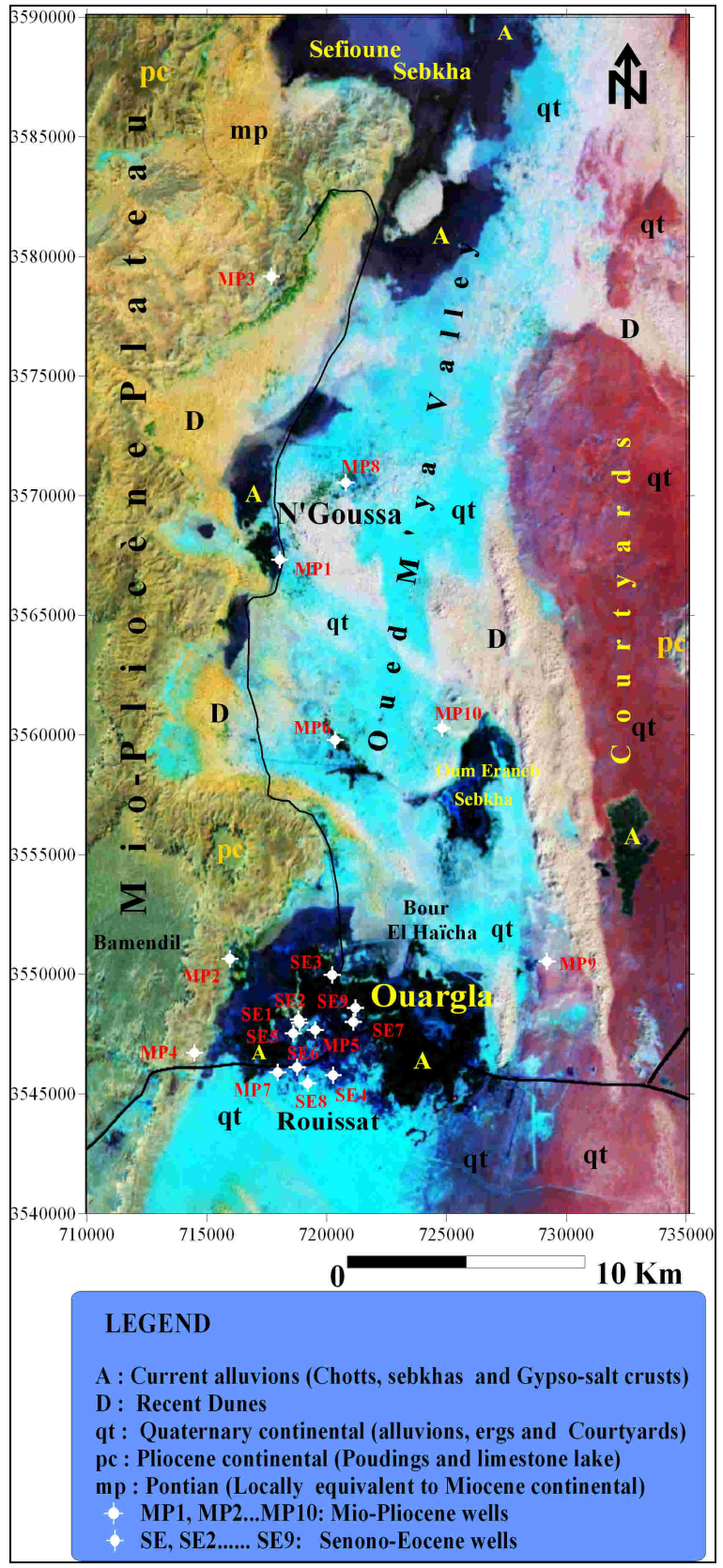

Fig. 1: Location of the studied area and the individual sampled wells

The fluoride, phosphorus, nitrates, sulphates and chlorides were measured using the spectrophotometer type DR2000 (HACH). Calcium, sodium and potassium were measured using flame spectro-photomètry (410 CORNING). Magnesium measured by complexometry, with Ethylene-diaminetetracetic titration (EDTA) $\left(\mathrm{Mg}^{2+}=\mathrm{TH}-\mathrm{Ca}^{2+}\right)$. The $\mathrm{pH}$ and 
bicarbonates measured using a pH-meter type E632 (METLOOHM) with the data we conducted a simulation to natural evaporation.

Data of four wells (MP4, MP7, SE4 and SE6), is used, where analysis are conducted in laboratory of water chemistry of Ouargla University. The data are not limited to major elements and fluoride, but are extended to others, such as temperature (in-situ measured) and phosphorus.

The software «Statistica.v6.1 ${ }^{[11]}$ was used for the statistical treatment basing on the Ascending Hierarchical Classification (AHC) method.

The method consists to classify "p" variables and "n" observations constructing a matrix of distances between variables and observations. Then a rule for calculating the distances between separated groups of variables or observations is defined. Groups whose distance is the lowest meet together in a couple (according to this criterion) and the process is repeated until a complete regrouping of classes ${ }^{[10] .}$ A dendrogram or classification tree can represent the Ascending Hierarchical Classification (AHC).

The geochemical survey was carried out by simulating the natural evaporation (temperature of the sample) or isothermal $\left(25^{\circ} \mathrm{C}\right)$, using the software chemical thermodynamics 〈phreeqci.v.2.12»> ${ }^{[8]}$. The calculation of the saturation index $(\mathrm{SI}=\log (\mathrm{Q}) / \log$ $\left(\mathrm{K}_{\mathrm{ps}}\right)$ ) of dissolved minerals in water was conducted using the law of Debye-Hückel ${ }^{[8]}$, considering that the state of equilibrium done in the interval -0.5-+0.5.

The chemical monitoring of the fluoride concentration in water depends mainly on the state of saturation towards the fluorite $\left(\mathrm{CaF}_{2}\right)$. If water is undersaturated, the fluoride concentration reflects, generally, the available amount within the washed rock. However, if water is saturated, the fluoride concentration is limited by the solubility constant value $\left(\mathrm{K}_{\mathrm{ps}}\right)$ of fluorite dissolution reaction:

$\mathrm{CaF}_{2 \text { solid }} \mathrm{Ca}^{2+}$ aqueous $2 \mathrm{~F}_{\text {aqueous; }}$ with, $\log \mathrm{K}_{\mathrm{ps}}=-10.10^{[8]}$

Fluoride in the waters of sedimentary rocks: The solid forms of fluorides, which can be likely found in natural waters, are: fluorite $\mathrm{CaF}_{2}$ and sellaite $\mathrm{MgF}_{2}$. The fluorapatite $\left(\mathrm{Ca}_{5}\left(\mathrm{PO}_{4}\right)\right.$ 3F) may be found in the environment when phosphorus is present. The fluoride is the most abundant halogen in sedimentary rocks ${ }^{[12]}$. The fluorite and fluorapatite of the phosphatic basins' rocks are the main fluoride minerals ${ }^{[6]}$. If there are not phosphates, the origin should be checked in the clayey roof of the aquifers.

\section{RESULTS}

The hydro-chemical characteristics of water results, show high values of conductivity ranging from 1840-4090 $\mu \mathrm{S} \mathrm{cm}$ and beyond fluoridation of drinking water standards, or $0.6-0.8 \mathrm{mg} \mathrm{L}^{-1}$, associated with $\mathrm{pH}$, tending towards alkalinity, between 7.34 and 8.7. Three chemical elements show dominant concentrations $\mathrm{SO}^{2-}, \mathrm{Cl}^{-}$and $\mathrm{Na}^{+}$varying between 200 and $942 \mathrm{mg} \mathrm{L}^{-1}$, followed by $\mathrm{Ca}^{2+}, \mathrm{Mg}^{2+}$ and $\mathrm{HCO}^{-}$ 3 with variable concentrations from $86-238 \mathrm{mg}$ $\mathrm{L}^{-1}$.

The concentrations of fluoride observed in the CT water table (Mio-Pliocene and Senono-Eocene) vary between 0.90 and $1.42 \mathrm{mg} \mathrm{L}^{-1}$.

The concentrations recorded in their entirety exceed $1 \mathrm{mg} \mathrm{L}^{-1}$ (74\% of samples) and remain beyond the optimum dose $\left(0.7 \mathrm{mg} \mathrm{L}^{-1}\right)$ estimated using the formula of Galagan ${ }^{[5]}$ for the people of the studied region. The highest concentrations come mainly from waters of Mio-Pliocene, where we recorded: 1.27, 1.30, $1.31,1.33$ and $1.42 \mathrm{mg} \mathrm{L}^{-1}$, respectively, in wells MP8, MP9, MP6, MP10 and MP3, located in the north area of Ouargla city.

Phosphorus levels recorded in the waters MP4, MP7, SE4 and SE6 vary between 0003 and 0028 $\mathrm{mg} \mathrm{L}{ }^{-1}$. The natural temperature of water measured in four wells mentioned above varies between 20 and $23^{\circ} \mathrm{C}$.

Three chemical facies were observed (Fig. 2), two of which two remain characteristical: The first one is sodium chloride Cl-Na whose conductivity is more than $2600 \mu \mathrm{S} \mathrm{cm}^{-1}$ in the Mio-Pliocene water. The second one is $\mathrm{SO}_{4-}-\mathrm{Mg}$ whose conductivity is less than 2000 $\mu \mathrm{S} . \mathrm{cm}^{-1}$ and is the mainly observed facies in the water of Senono-Eocene.

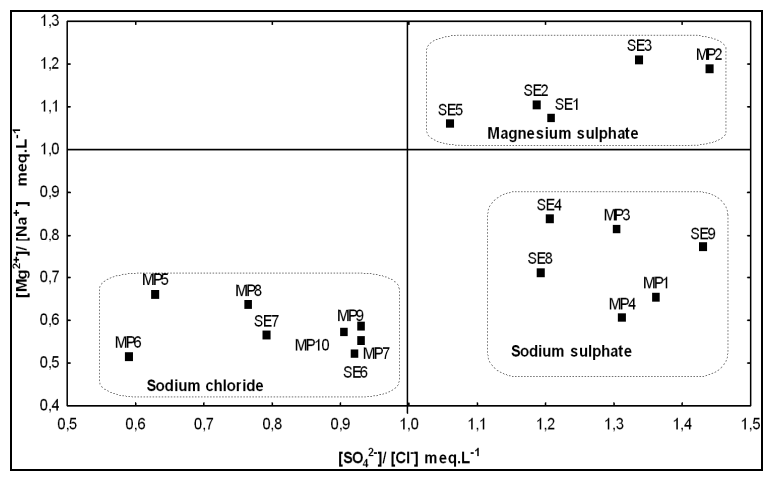

Fig. 2: Spatial distribution of chemical facies in the CT aquifer (February 2002) 
The third facies is $\mathrm{SO}_{4}-\mathrm{Na}$ whose conductivity is more than $2000 \mu \mathrm{S} \mathrm{cm}^{-1}$. It is found in the water of both aquifers of CT.

\section{DISCUSSION}

\section{Origins of fluoride in water:}

Statistical analysis: The dendrograms of variables and observations (Fig. 3 and 4) show that four (04) wellcorrelated families can be distinguished:

- The first-family characterizes the exclusivity of the parameter (EC), highly high in the Mio-Pliocene drill (MP5) located in Ouargla city

- The second-family containing the evaporitic pole $\left(\mathrm{Na}^{+}, \mathrm{Cl}^{-}\right.$and $\left.\mathrm{SO}_{4}{ }^{2-}\right)$, characterized by high salinity, whose facies is $\mathrm{Cl}-\mathrm{Na}$ or $\mathrm{SO}_{4}-\mathrm{Na}$ and includes wells drilled primarily in the in the Mio-Pliocene water table. It shows high concentrations of chlorides, sulphates and sodium, corresponding to gypsum $\left(\mathrm{CaSO}_{4} \cdot 2 \mathrm{H}_{2} \mathrm{O}\right)$ and the halite $(\mathrm{NaCl})$, of geochemical structure of the aquifer formations

- The Third familly, characterized by the presence of carbonated pole $\left(\mathrm{Ca}^{2}, \mathrm{Mg}^{2+}\right.$ and $\left.\mathrm{HCO}_{3}{ }^{-}\right)$rich in calcium, magnesium and bicarbonate, corresponding to the limestone $\left(\mathrm{CaCO}_{3}\right)$ and dolomites $\left(\mathrm{CaMg}\left(\mathrm{CO}_{3}\right)_{2}\right)$ of the Senono-Eocene water, represented by the wells SE1, SE2, SE3, SE4 and SE8. The facies of this family is $\mathrm{SO}_{4-}-\mathrm{Mg}$

- The Fourth-familly is relatively heterogeneous. Its facies is $\mathrm{SO}_{4}-\mathrm{Na}$, containing wells in the MioPliocene: MP1, MP3 and MP8 and SenonoEocene: SE5, SE7 and SE9, with alkaline $\mathrm{pH}(7.6<$ $\mathrm{pH}<8.7$ ), which includes nitrate, potassium and fluoride parameters

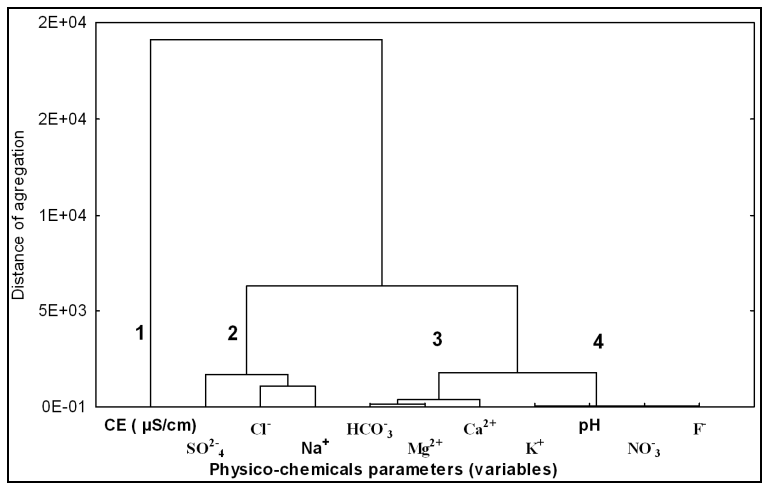

Fig. 3: Dendrograms of physico-chemical parameters in water of the CT aquifer
Such family could therefore represent water pollution under the effect of a partial increasing pressure of $\mathrm{CO}_{2}$, or any possible alteration of clays, under the effect of a relatively high alkalinity of water (Fig. 3), especially in the case of fluoride and potassium.

The richness of water elements $\mathrm{Na}^{+}, \mathrm{Cl}^{-}$and $\mathrm{SO}_{4}^{2-}$ is due to the dissolution of evaporitic formations. However, the elements $\mathrm{Ca}^{2+}$ and $\mathrm{Mg}^{2+}$, generated from two sources: gypseous formations (evaporites) and limestone in the case of carbonates.

Thermodynamics simulation:

Geochemical monitoring of fluorite: The balance compared to the fluorite $\left(\mathrm{CaF}_{2}\right)$, in water of the complex terminal, resulting in a straight line of slope 1 in the diagram (Fig. 5), which is related to $\log \left(\mathrm{Ca}^{2+}\right)$ versus $2 \log \left(\mathrm{F}^{-}\right)$, in terms of activities $\mathrm{Ca}^{2+}$ and $\mathrm{F}^{-}$.

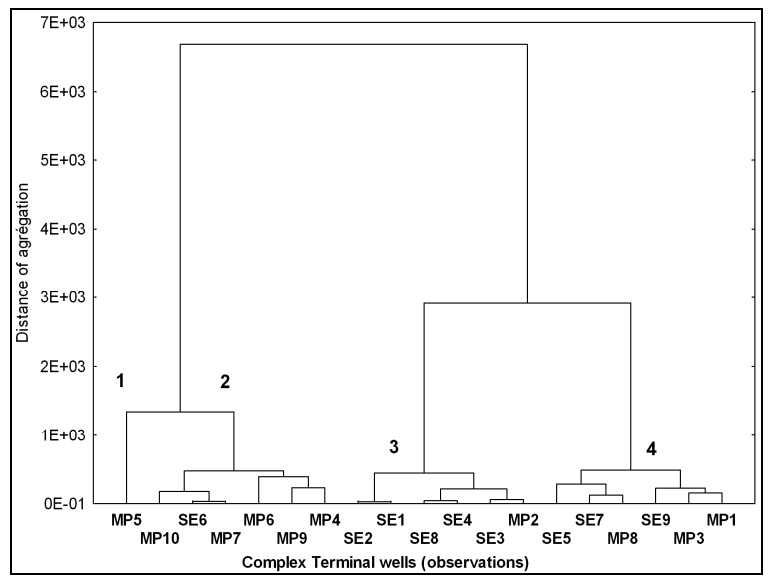

Fig. 4: Dendrograms of samples in the waters of the CT aquifer

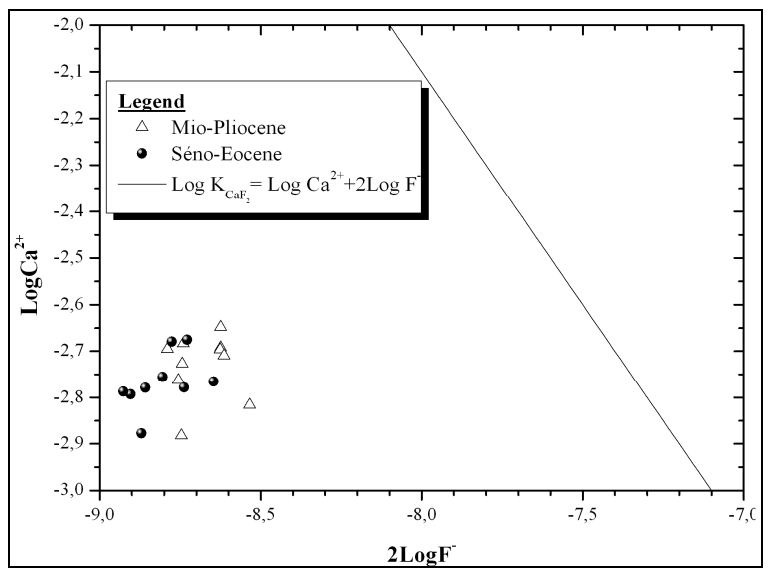

Fig. 5: Balance diagram by fluorite in waters of the CT aquifer 
Am. J. Applied Sci., 6 (5): 876-881, 2009

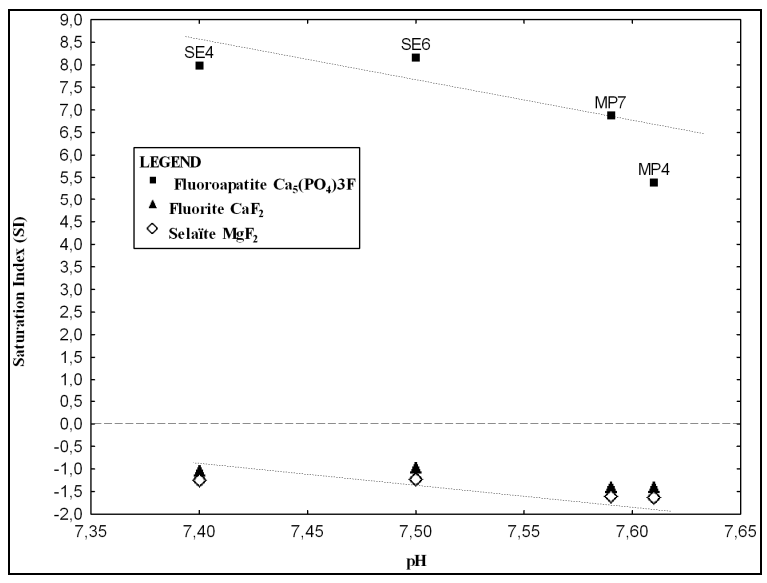

Fig. 6: Evolution of the saturation index of fluoride minerals depending on water alkalinity (simulation to natural evaporation)

The diagram shows an under-saturation of water towards fluorite. The analysis of the cloud of points on the diagram reveals an evolution toward a branch of calcium, indicating that there might be other minerals, which control the area of calcium and/or minerals, which control the area of fluoride, other than fluorite. While the correlation between concentrations of calcium and fluoride in water provides additional information. The correlation is of an average quality $(\mathrm{r}=0.45)$. However, this is contradictory for the undersaturated waters in fluorite. Hence, there may be other calcium fluoride minerals, which could control this element in water.

Saturation index and fluoridation of water: The calculation of water saturation index by fluoride minerals (Fig. 6) reveals an over-saturation (precipitation) by the fluoroapatite $\left(\mathrm{Ca}_{5}\left(\mathrm{PO}_{4}\right) 3 \mathrm{~F}\right.$ and an under-saturation by the couple fluorite $\left(\mathrm{CaF}_{2}\right)$ and sellaïte $\left(\mathrm{MgF}_{2}\right)$ in all samples (simulation to natural evaporation). The saturation index had highlighted a plausible relationship between fluoride and phosphate minerals, which may participate in the aquifer matrix. The relation $\mathrm{pH}-\mathrm{IS}$, shows saturation index towards the fluoroapatite (IS $>>0.5)$, the fluorite and the sellaite decrease as the $\mathrm{pH}$ increases (Fig. 6).

The pre-acquired statistics, showing the relationship $\mathrm{pH}$-potassium-fluoride, which undoubtedly contributes to any alteration of clay, under the effect of the alkalinity of water increasing, which leads to more solubility of chemical elements such as fluoride and potassium. Indeed, the saturation index of dissolved minerals (simulation to isotherm $\left(25^{\circ} \mathrm{C}\right)$ evaporation) in water shows the sensitivity of carbonated minerals: dolomite, calcite, aragonite, towards precipitation and evaporitic minerals, especially gypsum and anhydrite (Fig. 7).

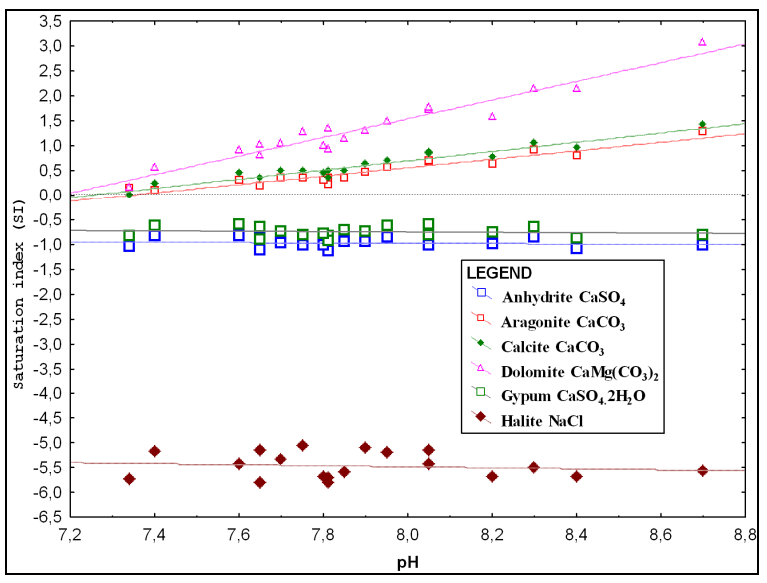

Fig. 7: Evolution of the saturation index minerals depending on water alkalinity (simulation to isotherm $\left(25^{\circ} \mathrm{C}\right)$ evaporation)

The carbonates precipitation and dissolution of evaporates (Fig. 7) and fluorite (Fig. 6) increase proportionally with alkalinity $(\mathrm{pH})$ of water, reflecting the character of the common ion wish is calcium. It shoes that the alkali $(7.6<\mathrm{pH}<8.7)$ (Fig. 7) of water helps with ionic exchanges between fluorinated minerals and hydroxide group $\left(\mathrm{OH}^{-}\right)$, which induces the solubility of fluoride, according to the studies ${ }^{[1,2,6]}$.

\section{CONCLUSION}

The study highlights the hydro-geochemical origin of fluoride, rarely examined in the Algerian Sahara, to valorise the relation « characteristics" of the studied aquifer. The water is characterized by a high salinity, combined with a fluoridation that can harm the health of population. The concentrations of fluoride found vary between $1 \mathrm{mg} \mathrm{L}^{-1}$ and $2.03 \mathrm{mg} \mathrm{L}^{-1}$, exceeding $1 \mathrm{mg} \mathrm{L}^{-1}$ in $74 \%$ of sampled wells. The method of Ascending Hierarchical Classification allowed us to individualize two levels of aquifers in the Complex Terminal. According to their lithological nature in two distinct poles, namely the carbonate pole $\left(\mathrm{Ca}^{2+}, \mathrm{Mg}^{2+}\right.$ and $\left.\mathrm{HCO}_{3}{ }^{-}\right)$on the ground of Senono-Eocene and the evaporite pole $\left(\mathrm{Na}^{+}, \mathrm{Cl}^{-}\right.$and $\mathrm{SO}_{4}{ }^{2-}$ ) on the Mio-Pliocene. The thermodynamics simulation shows that the increasing alkalinity of water in contact with the aquifer during long periods of stay, decreases the chemical activity of calcium and helps with alteration of clayey minerals and fluoride as a necessary condition for a possible fluorite mineralization. 
Knowing the origin of that fluoridation leads to possible solutions, through the optimization of a water treatment meets the standards.

\section{REFERENCES}

1. Barbiero, L., V. Valles and A. Regearg, 1995. Precipitation of fluorite and geochemical control of calcium in alkaline soils of Niger. Consequences for a quantitative estimate of the evolution of geochemical soil. CR. Acad. Sci. Paris., 321: 11471154.

2. Chernet, T., Y. Travi and V. Valles, 2001. Mechanism of degradation of the quality of natural water in the lakes region of the Ethiopian rift valley. Water Res., 35: 2819-2832. DOI: 10.1016/S0043-1354(01)00002-1.

3. Djellouli, H.M., S. Taleb, D. Harrache-Chettouh and S. Djaroud, 2005. Physicochemical quality of drinking water of Southern Algeria: Study of excess mineral salts. Sante, 15: 109-112. http://cat.inist.fr/?aModele $=$ afficheN\&cpsidt $=1697$ 1112.

4. Guendouz, A., A.S. Moula, W.M. Edmunds, K. Zouari, P. Shand and A. Mamou, 2003 Hydrogeochemical and isotopic evolution of water in the complexe termrminal aquifer in the Algerian Sahara. Hydrogeol., J., 11: 483-495. DOI: 10.1007/s10040-003-0263-7.
5. Galagan, D.J. and Jack R. Vermillion, 1957. Determining optimal fluoride concentrations. Public Health Rep., 72: 491-493. http://www.pubmedcentral.nih.gov/articlerender.fc gi? artid=2031310.

6. Mazet, P., 2002. Groundwater rich in fluoride in the world. DEA. Science of water in the continental environment. http://horizon.documentation.ird.fr/exldoc/pleins_textes/divers4/010031017.pdf.

7. Ould Baba Sy, M., 2005. Paleo recharge and recharge the aquifer system of the Sahara Septentrional.

http://www.cig.ensmp.fr/ hydro/THE/OULD_BA BA_SY.pdf.

8. PHREEQCI, 2005. A graphical user interface for the geochemical computer program PHREEQC. http://wwwbrr.cr.usgs.gov/projects/GWC_coupled/ phreeqci/.

9. Rodier, J., 1985. The Analysis of Water. 7th Edn., Dunod, Paris, ISBN: 2040156151.

10. Saporta, G., 1990. Probability Data Analysis and Statistics. 1st Edn., Téchnip, Paris, ISBN: 2-71080565-0, pp: 493.

11. StatSoft France, 2003. STATISTICA, data analysis software.

12. Wedepohl, K.H., 1975. Handbook of geochemistry. J. Applied Crystallograph., 2: 498498. DOI: $10.1107 /$ S0021889875011120. 